\title{
ARÚSPICES INDIANOS, KINDZU E SURENDRA VALÁ: MÁQUINAS DE GUERRA NA GEOPOLÍTICA DO OCEANO ÍNDICO PÓS-COLONIAL ${ }^{1}$
}

Jorge Alves Santana (UFMG)

Resumo: Em Terra sonâmbula, de Mia Couto, acompanhamos os desdobramentos socioestéticos dos diários de Kindzu na sociedade moçambicana em guerra civil. O protagonista, em sua formação individual e coletiva, relaciona-se com o indiano Surendra Valá, que o educa em relação aos fatos da globalização contemporânea. Somos, assim, apresentados a certa geopolítica do Oceano Índico que remonta à colonização lusitana, exposta em Os Lusíadas. Refletiremos, nesse contexto, sobre aspectos dessa transnacionalidade entre Moçambique e Índia. Tais mobilidades espaciais são perspectivadas por reflexões póscolonialistas, como as de Deleuze; Guattari (1997), Augé (2010; 2012), Anderson (1989; 2008), Fanon (1979), Spivak (2008; 2010), e Harvey (2003).

Palavras-Chave: Terra sonâmbula; Os Lusíadas; Oceano Índico; Mobilidades transnacionais contemporâneas.

Abstract: In Mia Couto's Sleepwalking Land we see the cultural and political developments of Kindzu's diaries in mozambican society in civil war. Kindzu, in his psicossocial formation, connects with the indian Surendra Valá, who teaches him about facts of the contemporary globalization. We are presented this way to certain geopolitics of the Indian Ocean which rebuilds to the portuguese colonization, exposed in The Lusiadas. We'll reflect upon this transnationality between Mozambique and India. Such spacial mobilities are contemplated by postcolonial studies, such as Deleuze; Guattari (1997), Augé (2010; 2012), Anderson (1989; 2008), Fanon (1979), Spivak (2008; 2010), e Harvey (2003).

Keywords: Sleepwalking Land, The Lusiadas, Indian Ocean; Contemporary transnational mobilities.

1 Título do artigo em inglês: "INDIAN HARUSPICES, KINDZU AND SURENDRA VALÁ: WAR MACHINES IN THE GEOPOLITICAL POSTCOLONIAL INDIAN OCEAN" 
E ele me passava um pensamento: nós, os da costa, éramos habitantes não de um continente, mas de um oceano. Eu e Surendra partilhávamos a mesma pátria: o Índico.

(COUTO, 2007)

O espaço liso e o espaço estriado, o espaço nômade e o espaço sedentário, o espaço onde se desenvolve a máquina de guerra e o espaço instituído pelo aparelho de Estado, não são da mesma natureza.

(DELEUZE; GUATTARI, 1997).

É preciso sair do cerco culturalista e promover o indivíduo transcultural, aquele que, adquirindo o interesse por todas as culturas do mundo, não se aliena em relação a nenhuma delas.

É chegado o tempo da nova mobilidade planetária e de uma nova utopia da educação. Mas só estamos no começo dessa nova história que será longa e, como sempre, dolorosa.

(AUGÉ, 2010)

\section{INTRODUÇÃO}

O romance Terra sonâmbula (1992), do escritor moçambicano Mia Couto, ${ }^{2}$ representa/expressa uma das mais sangrentas guerras do Continente Africano.. ${ }^{3}$ A guerra civil moçambicana, após sua independência de Portugal, foi tensionada, entre outros fatores, pelo projeto político afromarxista em confronto com o projeto neoliberal europeu,

2 Mia Couto mantém produtivo ofício de escrita literária e de outras produções ativistas quanto a causas sociais moçambicanas. Seu trabalho está disposto em plataformas intermidiáticas e despertam vivo interesse internacional. Para mais informações sobre o autor, seu conjunto de obras e seu ativismo sociocultural, queira acompanhar o engenhoso site Official Website: http:// www.miacouto.org Acesso em 10.Jun.2016.

3 Sobre a situação de colonização e pós-colonização de Moçambique, relativamente parecida com a de Angola, acompanhamos os estudos de João Paulo Borges Coelho (2015), pesquisador da Universidade Eduardo Mondlane, uma das instituições mais relevantes do país. Para compreendermos os demais processos de colonização e de descolonização de outros países africanos, seguimos os estudos de Tutikian: 2006 e Ferreira: 1975. Quanto ao caso brasileiro em particular, estamos perspectivados pelo já clássico estudo de Bosi: 1992. 
sendo que esse último projeto direciona o governo ao final de tal conflito. A engenharia dessa narrativa é montada, pois, pelos destroços do imperialismo luso-tropical, apontando para possibilidades da reconstrução/reinvenção da nação, tendo em vista a desejada democracia multipartidária e multiétnica.

Neste contexto de projetos políticos, sociais e culturais acompanharemos a narrativa de Mia Couto também em suas relações com elementos culturais da sociedade indiana, presentes no personagem indiano Surendra Valá. Essa figura terá papel determinante na formação de um dos protagonistas, o jovem Kindzu, autor dos diários que dinamizam os núcleos acionais da narrativa. Para entendermos melhor essa conexão, voltaremos um pouco no tempo para observarmos como tais personagens são influenciados pelo projeto expansionista do mercantilismo/ imperialismo lusitano, expresso já na poesia épica de Os Lusíadas, de Luís Vaz de Camões; particularmente no que diz respeito a alguns aspectos definidores da geopolítica do Oceano Índico, espaço unificador da costa leste africana com a costa oeste indiana.

Dessa forma, refletimos sobre vínculos socioestéticos diacrônicos entre representações culturais do início dos processos de colonização portuguesa e certo corolário contemporâneo, expresso pelas condições pós-coloniais. 
Terra Sonâmbula nos traz dois grupos de moçambicanos, nesse contexto de guerra civil. Um dos grupos é constituído por um velho, Tuahir, e por um garoto, Muidinga, refugiados civis do contexto bélico nacional. O outro, por Kindzu e sua família, bem como por amigos de sua aldeia à beira do Índico e companheiros de vários lugares pelos quais ele passa em sua procura pelos guerreiros Naparamas e pelas tentativas de formação pessoal que visam sua participação na construção coletiva de sua nação.

A narrativa é montada por suas linhas de ação dramática, dispostas em doze capítulos, sendo que há uma divisão simétrica para as duas narrativas encaixadas. Na primeira, acompanhamos Tuahir e Muidinga, que vagam por uma estrada cronicamente afetada pelos destroços da guerra, encontrando os diários de um jovem moçambicano morto. Na segunda, Kindzu, o moçambicano que escreve os diários, narrando sua vida envolta em variadas aventuras em torno de sua vida familiar e de certa coletividade da vida moçambicana em guerra civil. Os primeiros lerão os diários do segundo, em dinâmica de mise em abyme, que unirá universos diversos na necessária situação de se compreender e de se construir as espacialidades e identidades dos lugares e dos não lugares em tempos pós-coloniais. 
A constatação exposta no início do romance é o da brutal destruição causada pela guerra que atinge tanto a população local quanto aquela dos imigrantes em Moçambique. Vejamos esse começo, pelo olhar dos diários de Kindzu:

Naquele lugar, a guerra tinha morto a estrada. Pelos caminhos só as hienas se arrastavam, focinhando entre cinzas e poeiras. A paisagem se mestiçara de tristezas nunca vistas, em cores que se pegavam à boca. Eram cores sujas, tão sujas que tinham perdido toda a leveza, esquecidas da ousadia de levantar asas pelo azul. Aqui, o céu se tornara impossível. E os viventes se acostumaram ao chão, em resignada aprendizagem da morte. (COUTO, 2007, p.2).

Para essa aprendizagem sobre a guerra e a morte, e de suas variadas causas e das consequências atuais, no entanto, sabemos que um imigrante indiano, o velho e sábio Surendra Valá, funcionará como elemento propedêutico e dialético no sentido de mostrar novos valores, crenças e comportamentos que capacitarão o jovem refugiado a entender, com maior consciência reflexiva, o contexto bélico no qual está imerso. Um desses saberes será aquele pertinente ao fato de se compreender as fronteiras estabelecidas historicamente entre os povos como um dispositivo político a ser flexibilizado e, no caso, compreendido como espaços heterogêneos e 
variados que formam, arbitrariamente, certa geopolítica em fluxo diacrônico.

\section{ARÚSPICES E UM NGANGA NA GEOPOLÍTICA CULTURAL DO OCEANO ÍNDICO}

Das formações discursivas que nos expõem as conquistas portuguesas de colônias em vários continentes, possui destaque a poesia épica de Camões. O poema Os Lusíadas (1572) consolida a tradição da suposta bravura, da dignidade e das nobrezas civilizatórias das quais esse povo europeu revestia seu projeto expansionista político-econômico. Atemo-nos aqui ao instigante episódio no qual a frota de Vasco da Gama entra em Calecute, cidade a oeste na costa indiana.

Parte da comitiva colonizadora entrará em contato com as autoridades superiores desse reino oriental. Em meio a tramas de diplomacias enviesadas que procuram conhecer a maior quantidade de dados possíveis da sociedade a ser colonizada, vemos que os sacerdotes do Samorim, orientados pelo deus Baco, conseguirão antever os pragmáticos objetivos políticos da comitiva lusa. Assim, alertarão o governante para se armar e enfrentar os visitantes que, mesmo aparentemente apenas visitantes a procura de corriqueiros acordos comerciais e culturais, na verdade trazem sérios riscos políticos para a sociedade local, o que poderá ocasionar o 
cativeiro e a destruição de sua autonomia e independência. Tais sacerdotes e profetas eram chamados de arúspices e aconselhavam os governantes em suas decisões políticas. Vejamos como tais personagens profetizadoras agem nessa função de desvelar os interesses povo luso em sua aparente viagem de contatos multiculturais:

45

Entretanto, os arúspices famosos

$\mathrm{Na}$ falsa opinião, que em sacrifícios

Antevêm sempre os casos duvidosos

Por sinais diabólicos e indícios, Mandados do Rei próprio, estudiosos,

Exercitavam a arte e seus ofícios, Sobre esta vinda desta gente estranha, Que às suas terras vem da ignota Espanha.

46

Sinal the mostra o Demo, verdadeiro,

De como a nova gente lhe seria Jugo perpétuo, eterno cativeiro,

Destruição de gente e de valia.

Vai-se espantado o atónito agoureiro

Dizer ao Rei (segundo o que entendia)

Os sinais temerosos que alcançara

Nas entranhas das vítimas que olhara.

(CAMÕES, 2002, p.399).

A voz narrativa do poema é franca e pontual na valoração de tais conselheiros; eles representariam vozes equivocadas de reles vítimas das tramas perversas do deus Baco, que tenta de todas as formas, defender o que tradicionalmente é o seu território oriental da entrada de povos desconhecidos. A profecia desses arúspices insere no 
poema épico, mesmo que de modo indireto, a perspectiva dialógica sobre o projeto de conquista da frota lusa. Mesmo de caráter de negativo, já nos alerta para fissuras sistêmicas na construção da nova geopolítica que os povos europeus tentarão produzir nessa parte do Oceano Índico e em outros tantos lugares que secularmente ficarão sobre o jugo imperialista da coroa portuguesa.

Séculos mais tarde, agora na trama de Mia Couto, seguimos sujeitos imersos em uma guerra civil causada também pelo projeto expansionista do povo luso. A ação, como já mencionamos, ocorre em plena guerra civil causada, paradoxalmente, pela independência de Moçambique, que ocorre em 1975. A sociedade civil estertora em enfretamentos de grupos sociais defensores de projetos sociais e políticos diferentes para a reconstrução nacional. Nesse contexto, o jovem Kindzu deixará a casa de sua família para compreender o que ocorre em seu país e poder, de modo ativo, tomar partido quanto ao fim do conflito civil e quanto ao projeto de reconstrução da nação a ser implementado. Esse percurso de formação será registrado de modo sistemático em seus diários ${ }^{4}$,

4 Instiga-nos que os diários de Kindzu, escritos através da focalização homodiegética autotélica, dão o tom da voz relativamente autônoma e crítica deste protagonista. Ou seja, um jovem negro moçambicano, de classe social trabalhadora e de baixa renda, dominando a escrita oficial e representado o mundo no qual se insere, de acordo com sua formação psicossocial. Sobre tal estratégia composicional efetivada por Mia Couto, lembramo-nos de Gayatri C. Spivak (2008; 2010) que nos alerta para a necessidade de o intelectual/artista deixar o subalterno falar por conta de seu estrato sociocultural. Para ela, é habitual defendermos causas de um povo em condição de vulnerabilidade social, considerando-o como coletividade homogênea. 
que possuem valor fundante para a economia da narrativa.

Kindzu perambulará por espaços urbanos, rurais e marítimos para conhecer aquilo que ouvia em sua pequena aldeia natal. Encontrará a população moçambicana em acentuada diáspora: ${ }^{5}$ famílias expulsas de suas casas; grupos populacionais perambulando sem rumo pelo país, instituições governamentais sucateadas e disfuncionais; dispositivos de guerrilhas por todos os lugares; campos de refugiados repletos de miseráveis; fuga de grande número de pessoas para países vizinhos; enfim, miséria, truculência bélica e quase ausência de dispositivos mantenedores dos direitos humanos básicos.

Ao sair de casa, o jovem sente-se perturbado em deixar a família. Seu pai morrera de desgosto por ver a situação política do país. Sua mãe não compreendia como poderia resolver as questões básicas de sobrevivência familiar. Seu irmão alegoricamente fora transformado/fantasiado pelo

\footnotetext{
Que devemos nos preocupar, segundo Spivak, em deixar o povo subjugado ter condições de construir e consolidar sua própria capacidade de representação e de expressão dos seus múltiplos contextos. Assim, a codificação de identidades heterogêneas, mesmo que através de estratégias do uso de certos essencialismos, seria uma necessidade para se tensionar interesses presentes em contextos pós-coloniais, no que diz respeito a agências e soberanias dos agentes sociais envolvidos no processo.

5 Acompanhamos o conceito de diáspora em Stuart Hall (2001), principalmente quando esse pensador multiculturalista também desloca o fenômeno para contextos de desterritorialização psicossocial em microescala, além dos contextos de macroescala. Diáspora então se abre para explicitar e marcar contextos de mobilidades forçadas, seja no âmbito coletivo maior de um povo, seja também no âmbito das singularidades dos indivíduos frente a sua dialógica dimensão subjetiva e às instituições que existem em um rede mais próxima de sua coexistência.
} 
pai em um animal, um frango, que vivia no galinheiro para se livrar de uma possível batida policial no lugar. Como sair de casa para mergulhar na necessária mobilidade propedêutica, fonte para a produção de condições capazes de estancar a guerra civil e construir alternativas sociais para a nação? Para isso, Kindzu consulta um sábio do lugar, um velho nganga, que Ihe acena certo horizonte acional:

O velho nganga atirou os ossinhos mágicos sobre a pele de gazela. Os ossos caíram todos numa linha, disciplinados. - Está ver, todos linhados? Isso quer dizer: você é um homem de viagem. E aqui vejo água, vejo o mar. O mar será tua cura, continuou o velho. A terra está carregada das leis, mandos e desmandos. O mar não tem governador. Mas cuidado, filho, a pessoa não mora no mar. Mesmo teu pai que sempre andou no mar: a casa onde o espírito dele vem descansar fica em terra. - Vais encontrar alguém que te vai convidar para morar no mar. Cuidado, meu filho, só mora no mar quem é mar. Estas foram as falas do adivinho, palavras que nunca eu decifrei a fundura. (COUTO: 2007, p.16)

A consulta mística demonstra que o destino do rapaz está vinculado a espacialidades maiores que a de sua aldeia natal. Há, pois a legitimação cultural da necessária mobilidade educativa para que se possa construir mecanismos de enfrentamento/negociação com os dispositivos conflituosos de sua sociedade moçambicana. 
Os elementos essenciais da natureza em confluência com a existência humana são perspectivados pela fala desse nganga, com destaque para o mar, espaço para o qual fora a alma do falecido pai do rapaz. Essa alma, no entanto não se enraíza nesse elemento espacial aquático, pois, à noite, costuma voltar para a terra firme, para sua casa onde recebe preces, oferendas e atenção intergeracional. Nesse ponto da narrativa de Mia Couto, percebemos como se estabelece aquela espacialidade híbrida entre o mar e o continente; ou de outra forma, entre que seria o próprio da sociedade local e o alheio dos horizontes das alteridades identitárias possíveis e necessárias para as relações de coexistência em uma sociedade estratificada.

Por fim, retomando nossa atenção para a relação entre a cultura moçambicana contemporânea e aquela indiana da época das conquistas lusitanas, temos que tanto os sacerdotes indianos, que dinamizam os encontros/confrontos de portugueses com a sociedade oriental, quanto o feiticeiro moçambicano, que dinamiza os percursos psicossociais da formação de Kindzu, parecem funcionar como dispositivos culturais que nos fazem refletir sobre os processos de encontros e desencontros entre sociedades singulares. Essas sociedades, diferentes em sua historicidade particular, são forçadas a conviver em dinâmica de exclusão mútua pelos 
povos que as submetem aos seus interesses imperialistas. No entanto, também são sociedades que possuem condições multiculturais para vivenciarem dinâmicas de inclusão recíproca e de cooperação política quanto aos seus interesses múltiplos e heterogêneos.

\section{KINDZU E SURENDRÁ VALÁ: UM OCEANO TRANSNACIONAL}

Antes de partir para sua viagem de conhecimento e de reconhecimento amplos através da espacialidade agonizante e sonâmbula de Moçambique, Kindzu nos conta que tinha o hábito de conversar sobre vários temas com um singular comerciante de sua vila. Um dos últimos que permaneceram no lugar destruído pelo confronto civil. Trata-se do nosso já conhecido Surendra Valá. Das relações com esse comerciante indiano, o rapaz guardará princípios, crenças e valores que o preparam para se encontrar com um socius montado historicamente por formações discursivas como àquelas que estiveram atuantes no período de colonização e no contexto adverso da descolonização atual. Eis uma das sequências que nos demonstram a singular relação multicultural que ocorre entre um jovem moçambicano e um velho indiano, ambos em franco contexto diaspórico:

A guerra crescia e tirava dali a maior parte dos habitantes. Mesmo na vila, sede do distrito, as casas de cimento 
estavam agora vazias. As paredes, cheias de buracos de balas, semelhavam a pele de um leproso. Os bandos disparavam contra as casas como se elas lhes trouxessem raiva. Quem sabe alvejassem não as casas mas o tempo, esse tempo que trouxera o cimento e as residências que duravam mais que a vida dos homens. Nas ruas cresciam arbustos, pelas janelas espreitavam capins. Parecia o mato vinha agora buscar terrenos de que tinha sido exclusivo dono. Sempre me tinham dito que a vila estava de pé por licença de poderes antigos, poderes vindos do longe. Quem constrói a casa não é quem a ergueu mas quem nela mora. E agora, sem residentes, as casas de cimento apodreciam como a carcaça que se tira a um animal. Um único comerciante ficara na vila: Surendra Valá, indiano de raça e profissão. Eu gostava de lhe visitar, receber suas conversas, provar os cheiros de sua casa. Ele me servia comidas bem cheias, dessas dos olhos salivarem na língua. Sua mulher Assma não aguentara o peso do mundo. Todo o dia ela ficava na sombria traseira do balcão, cabeça encostada num rádio. Escutava era o quê? Ouvia ruídos, sem sintonia nenhuma. Mas para ela, por trás daqueles barulhos, havia música da sua Índia, melodias de sarar saudades do Oriente. (COUTO, 2007, p.11).

Essa espacialidade vivenciada, de modo dialógico e cooperativo, pelo jovem Kidzu aproxima-se mais do não lugar 
que do lugar, ${ }^{6}$ realidade desejada por ele e por grande parte de sua coletividade que agoniza por quase uma década. Seu princípio de sobrevivência o leva então para o comércio de Surendra Valá, "indiano de raça e profissão", cuja acolhida o tranquiliza e ameniza, mesmo que temporariamente, seu desespero pessoal e sua falta de perspectiva quanto a sua coletividade. ${ }^{7}$ Para ele, o acolhedor imigrante (refugiado?) tinha consciência do que se passava em Moçambique ou estava imerso no saudosismo de sua Índia, como parecia lhe indicar as músicas de sua origem étnica, que esse homem reiteradamente ouvia em seu rádio?

Nesse ponto de nosso estudo, pensamos nos interesses que podem unir esses dois personagens, aparentemente tão diferentes em seus objetivos de vida e, no entanto,

6 Para o antropólogo do cotidiano Marc Augé, um lugar corresponde ao espaço marcado pela historicidade ativada pela produção de sujeitos em contextos de coexistência ativa e consciente. Enquanto que para um não lugar, teríamos que: "Se um lugar pode se definir como identitário, relacional e histórico, um espaço que não pode se definir nem como identitário, nem como relacional, nem como histórico definirá um não lugar. A hipótese aqui defendida é a de que a sobremodernidade é produtora de não-lugares, isto é, de espaços que não são em si lugares antropológicos e que, contrariamente à modernidade baudelairiana, não integram os lugares antigos: estes, repertoriados, classificados e promovidos a 'lugares de memória', ocupam aí um lugar circunscrito e específico. (AUGÉ, 2012, p.73). Os dois tipos de espaços são intercambiáveis e/ou hibridizados, o que não lhes confere, pois, de modo singular, essencialidade ontológica.

7 A respeito dos sofrimentos pessoais e sociais que envolvem sujeitos em contextos políticos de descolonização, lembramo-nos, aqui, dos estudos valiosos de Franz Fanon, que nos ensina: "A descolonização, que se propõe mudar a ordem do mundo, é, está visto, um programa de desordem absoluta. Mas não pode ser o resultado de uma operação mágica, de um abalo natural ou de um acordo amigável. [...] A descolonização jamais passa despercebida porque atinge o ser, modifica fundamentalmente o ser, transforma espectadores sobrecarregados de inessencialidade em atores privilegiados, colhidos de modo quase grandioso pela roda viva da história. Introduz no ser um ritmo próprio, transmitido por homens novos, uma nova linguagem, uma nova humanidade. A descolonização é, em verdade, criação de homens novos." (FANON, 1979, p.26). 
tão próximos quanto aos seus lugares sociais construídos diretamente pelas influências de outras sociedades. Nesse caso, lembramo-nos das investidas e projetos imperialistas executados e mantidos até meandros do final do séc. $X X$ sobre esses povos. Resguardado o fato de que na Índia, tal influência perdurou por tempo menor, mas que, provavelmente, influenciou a formação de Surendra Valá, fazendo-o procurar abrigo em um país africano de Língua Portuguesa.

Esses lugares e não lugares estão, de acordo com Mia Couto, dispostos em uma ordem geopolítica que reflete procedimentos de certo imperialismo político e econômico de nossa realidade global. Moçambique e Índia ainda são sobredeterminados pelos dispositivos de submissão acionados por governos, sistemas financeiros, sistemas empresariais transnacionais que agem intensamente para estender seus campos de atuação e de domínio na aldeia global. Espaços da produção capitalista, com sua distribuição disfuncional de bens, serviços e lucratividade voraz, não cessam de se moldarem a espaços que se esbatem na nova ordem tida como pós-colonial. ${ }^{8}$

8 Sobre a constante e voraz produção de novos espaços e demandas para o capitalismo contemporâneo, bem como sobre as consequências desse processo em relação às sociedades submetidas a tais processos, David Harvey nos ensina que: "A produção do espaço, a organização de divisões territoriais totalmente novas do trabalho, a criação de complexos de recursos novos e mais baratos, de novas regiões como espaços dinâmicos de acumulação do capital e a penetração de formações sociais preexistentes por relações sociais e arranjos institucionais capitalistas (como regras de contrato e formas de gerenciamento da propriedade privada) proporcionam importantes maneiras de absorção de excedentes de capital e de trabalho. Essas 
Dessa forma, percebemos que a relação entre o jovem moçambicano e o velho imigrante indiano representam fenômenos humanos em curso nas tramas das transnacionalidades construídas, legitimadas e permitidas nas águas globalizadas do Oceano Índico. No entanto, antes de se arremeter ao mar, como o velho nganga profetizava, há de se cultivar a índole para se conhecer as cartografias que a terra sonâmbula é capaz de indicar.

\section{ESPAÇOS LISOS E A MÁQUINA DE GUERRA}

As peripécias das andanças de Kindzu, mais que cartografar as notórias ruínas do conflito pós-colonial moçambicano, resgatará tradições de lutas, como aquelas do lendário povo Naparama. Desse segmento étnico, diziam as lendas revolucionárias que surgiriam condições pragmáticas para a execução de um projeto de justiça social multiétnica capaz de reconstruir/reinventar o país. ${ }^{9}$

expansões, reorganizações e reconstruções com frequência ameaçam, contudo, os valores já fixados no lugar (incorporados à terra) mas ainda não realizados. Trata-se de contradição incontornável e aberta a uma interminável repetição, porque novas regiões também requerem capital fixo em infraestruturas físicas e ambientes construídos para funcionar com eficácia." (HARVEY, 2003, p.99).

9 Por invenção/construção/reinvenção/imaginação da nação, acompanhamos Benedict Anderson, que coloca o fenômeno do estabelecimento de um povo, de uma nação e afins, em bases históricas e não em bases naturais/espontâneas ou místicas, como certas perspectivas supõem. Para o autor: "Dentro de um espírito antropológico, proponho seguir a definição de nação: uma comunidade politicamente imaginada - e imaginada como sendo intrinsecamente limitada e, ao mesmo tempo, soberana. Ela é imaginada porque mesmo os membros das mais minúsculas nações jamais conhecerão, encontrarão ou nem sequer ouvirão falar da maioria dos seus companheiros, embora todos tenham em mente a imagem viva da comunhão entre eles". (ANDERSON, 2008, p.32). 
Um dos móveis acionais da narrativa é, portanto, o encontro com a tribo guerreira dos Naparamas, guerreiros que inclusive já tinham reordenado certas regiões do norte do país. O primeiro encontro de Kindzu com um dos membros desse grupo de guerreiros ocorre, de modo bastante simbólico, no comércio do amigo e tutor indiano:

O inesperado, então, sucedeu-se: um estranhíssimo homem entrou na loja. Trajava as mínimas vestes mas, na compensação, exibia colares, penas, fitas, enfeitações. E me deu fundo arrepio: nos braços se enrodavam vermelhos panos, pulseiras de xicuembo (Xicuembo: feitiço), exactos como aqueles que vi saindo da cabana do defunto meu pai. Fiquei de olhos presos na chegada figura. $\mathrm{O}$ ameaçador freguês também se emparvalhou, o fósforo se consumindo inteiro em seus dedos tremeluzentes. Assim mesmo, de mãos chamuscadas, saiu. O recém-chegado se aproximou do balcão e, em voz baixa, falou com Surendra. O volume do rádio não me deixava ouvir. Fui de novo à prateleira para diminuir o som. Quando me voltei já o homem tinha saído. Não pude guardar minha curiosidade: - Esse quem era? Esse é um naparama. Naparama? Nunca eu tinha ouvido falar em gente dessa. Surendra me explicou vagamente. Eram guerreiros tradicionais, abençoados pelos feiticeiros, que lutavam contra os fazedores da guerra. Nas terras do Norte eles tinham trazido a paz. Combatiam 
com lanças, zagaias, arcos. Nenhum tiro Ihes incomodava, eles estavam blindados, protegidos contra balas. (COUTO, p.13).

De presença singular, porém discreta, o tal guerreiro Naparama cumpre seu objetivo no comércio do indiano e se esvai no ar, assim como chegara. Cabe, portanto, a Kindzu lhe seguir os rastros para efetivar o projeto educativo das razões práticas, quanto ao seu papel de sujeito ativo nos campos da guerra civil e da morte, no qual seu país se transformou. Lutar contra os fazedores da guerra, eis um projeto que demanda alto grau de provimentos psicossociais. Como transformar-se em um guerreiro tradicional e abençoado pelos feiticeiros? Mia Couto parece nos responder com a ideia de que a mobilidade espacial talvez seja um forte elemento dos princípios dessa transformação.

Lembramo-nos, aqui, das reflexões que Gilles Deleuze e Félix Guattari fazem sobre os processos de subjetivações contemporâneos, que têm por base o predomínio das posições e disposições espaciais. Essas espacialidades possíveis funcionam como agenciamentos discursivos/existenciais de uma sociedade cuja produção capitalista é heterogêneas e esquizoide. Para tais pensadores e ativistas políticosociais, temos duas modalidades espaciais, dinamizadas por processos de inclusão, mesmo que paradoxal, que são o espaço liso e o estriado: 
O espaço liso e o espaço estriado, o espaço nômade e o espaço sedentário, o espaço onde se desenvolve a máquina de guerra e o espaço instituído pelo aparelho de Estado, - não são da mesma natureza. Por vezes podemos marcar uma oposição simples entre os dois tipos de espaço. Outras vezes devemos indicar uma diferença muito mais complexa, que faz com que os termos sucessivos das oposições consideradas não coincidam inteiramente. [...] Por isso, inclusive, os dois espaços não se comunicam entre si da mesma maneira: a distinção de direito determina as formas de tal ou qual mistura de fato, e o sentido dessa mistura (é um espaço liso que é capturado, envolvido por um espaço estriado, ou é um espaço estriado que se dissolve num espaço liso, que permite que se desenvolva um espaço liso?) (DELEUZE; GUATTARI, 1997, p.158-159).

A citação é um tanto extensa, porém precisa para chegarmos a um dos pontos centrais desse nosso breve estudo: o fato de que os dois personagens, aqui acompanhados de modo mais detido, consciente ou não tão consciente, agem com verdadeiras máquinas de guerra nas mobilidades espaciais que lhe são permitidas pelos complexos dispositivos de poder, que Ihes cerceiam conhecimentos, ações e reações. Os espaços estriados, densamente preenchidos por tradições próprias, alheias e híbridas, que encontramos em Terra 
Sonâmbula, convulsionados pela guerra civil moçambicana, impedem, de certa forma, a salutar mobilidade necessária para a reconstrução da nação. No entanto, também podem insuflar ações que dinamizam a capacidade prospectiva dos personagens. Essa capacidade será adquirida nas andanças pelos espaços lisos. Aqueles, por exemplo, dos desertos, dos mares, das estradas, da natureza ainda um tanto intocada pelas complexas ações humanas e abertas e flexíveis para tais interações.

Nesse contexto, percebemos que os diários de Kindzu registram núcleos variados de mobilidades por espaços lisos e estriados. Sua efetiva saída da aldeia natal, seu convívio em uma vila beira-mar, sua passagem por campos de refugiados, entres outros espaços afins. Mas, o que parece the oferecer mais condições para recolocar-se em novos lugares sociais é o percurso que faz pelas estradas moçambicanas e pelos deslocamentos nos espaços aquáticos. Nesses lugares predominantemente lisos, percebemos que o rapaz encontra meios que the possibilitam a reflexão sobre si, sobre os outros e, sobretudo, sobre as engenharias do socius de sua inserção prática.

Uma comunicação transversal ocorre entre esses dois tipos de espaços, os lisos e os estriados, que são vivenciados, 
sobredeterminados e sobredeterminadores da/pela escrita dos diários que serão encontrados posteriormente pelo velho Tuahir, que cuida do garoto Muidinga; personagens esses saídos de um tenebroso campo de refugiados, que darão continuidade aos projetos de Kindzu. Como mencionamos acima, essa dupla de refugiados nos é apresentada em uma segunda narrativa, acoplada ao que seria a central desse romance. Não focamos nossas reflexões nesse núcleo diegético, porém é esse núcleo que dará curso, de modo dialógico e dialético, às posições, disposições e valores ideológicos advindos do núcleo diegético de Kindzu e de Surendra Valá.

Tuahir e Muidinga, com suas estórias particulares de vida e de suas relações coletivas, darão continuidade à ação da máquina de guerra construída nos interstícios dos espaços lisos e dos estriados. O quantum energético para essa demanda provém muito da leitura que fazem dos diários de um jovem e desconhecido moçambicano, encontrado morto ao lado de um ônibus, em uma das anônimas estradas do país. Estradas, desertos, costas marítimas, mares, formam, pois uma das cartografias mais instigantes desse romance, que confia nos poderes propedêuticos da escrita e da leitura que abordam aspectos de contemporâneas geopolíticas 
pós-coloniais. São, pois, espaços que se imbricam, dandonos o sentido de mobilidades transversais emancipatórias e libertárias, como na fase em que acompanhamos o narrador nos apontar certo estado vivencial de Tuahir e de Muindiga. Estado esse proporcionado pelas leituras sistemáticas dos diários de Kindzu:

As ondas vão subindo a duna e rodeiam a canoa. A voz do miúdo quase não se escuta, abafada pelo requebrar das vagas. Tuahir está deitado, olhando a água a chegar. Agora, já o barquinho balouça. Aos poucos se vai tornando leve como mulher ao sabor de carícia e se solta do colo da terra, já livre, navegável. Começa então a viagem de Tuahir para um mar cheio de infinitas fantasias. Nas ondas estão escritas mil estórias, dessas de embalar as crianças do inteiro mundo. (COUTO, 2007, p.115).

\section{CONSIDERAÇÕES FINAIS}

Objetivamos, nesse breve estudo, estabelecer elos sociais e estéticos entre dois dispositivos discursivos produzidos pelas influências da cultura lusitana. Um dos episódios de Os Lusíadas, de Luís Vaz de Camões, e o romance Terra sonâmbula, de Mia Couto, oferecem-nos material para refletirmos sobre a produção de espaços transnacionais nos quais os sujeitos, envolvidos na produtividade de capitais de 
várias naturezas, podem se encontrar e produzir negociações na tentativa da compreensão, da desconstrução e da reconstrução de um socius que lhes é adverso, no decorrer de longa diacronia.

Uma das estratégias para a reconstrução de contextos coletivos em ruínas, como o expresso pela guerra civil moçambicana explorada por Mia Couto, parece ser a possibilidade das mobilidades pelos espaços lisos e estriados, nos quais os personagens estão insertos/incertos. Essa mobilidade dialética pode ser capaz de neutralizar o enraizamento étnico em bases exclusivas, quanto à dinâmica dos processos de globalização contemporâneos.

Percebemos, dessa forma, como os contatos entre a cultura indiana, tanto a da época de chegada dos portugueses em seu território quanto a contemporânea, e a cultura moçambicana dinamizam e produzem encontros fecundos. Tais encontros enriquecem a capacidade de resistência dessas sociedades perante os mecanismos de expropriação e de guerra impostos por governos contemporâneos ainda em intensa expansão imperial.

Personagens como o jovem moçambicano Kindzu e o velho indiano Surendra Valá nos sinaliza outras possibilidades de coexistências na geopolítica atual do Oceano Índico, tido 
também como espaço aberto para marcações humanas no registro da produção/imaginação de comunidades de fato cooperativas e justas. Dado o quadro, acreditamos ainda poder ouvir ecos daqueles aconselhamentos e admoestações feitos pelos arúspices indianos quanto aquela posição e disposição predatórias feitas pela frota lusitana, e por poderes políticos que lhe são correlatos nas cartografias índicas.

Dessa espacialidade sonâmbula, abordada por Mia Couto, também podem surgir estados de coexistência como esses, expressos quase ao término da caminhada de formação pessoal e coletiva de Kindzu:

No final, porém, restará uma manhã como esta, cheia de luz nova e se escutar uma voz longínqua como se fosse uma memória de antes de sermos gente. E surgirão os doces acordes de uma canção, o terno embalo da primeira mãe. Esse canto, sim, ser nosso, a lembrança de uma raiz profunda que não juram capazes de nos arrancar. Essa voz nos dar a força de um novo princípio e, ao escutála, os cadáveres sossegarão nas covas e os sobreviventes abraçarão a vida com o ingénuo entusiasmo dos namorados. Tudo isso se fará se formos capazes de nos despirmos deste tempo que nos fez animais. Aceitemos morrer como gente que já não somos. Deixai que morra o animal em que esta guerra nos converteu. (COUTO, 2007, p.118-119). 


\section{REFERÊNCIAS}

ANDERSON, Benedict (2008). Comunidades imaginadas: reflexões sobre a origem e a difusão do nacionalismo. Denise Bottmann (Trad.). São Paulo: Companhia das Letras.

AUGÉ, Marc (2012). Não lugares: introdução a uma antropologia da supermodernidade. Maria Lúcia Pereira (Trad.). Campinas: Papirus.

(2010). Por uma antropologia da mobilidade. Bruno César Cavalcanti e Rachel Rocha de Almeida Barros (Trad.). Maceió: EDUFAL/ UNESP.

BOSI, Alfredo (1972). Dialética da colonização. São Paulo: Companhia das Letras.

CAMÕES, Luís de (2000). Os Lusíadas. 4.ed. Lisboa: Instituto Camões/ Ministério dos Negócios estrangeiros.

COELHO, João Paulo Borges (2006). A "literatura quantitativa" e a interpretação do conflito armado em Moçambique. In www.ces.uc.pt/ estilhacos_do_imperio/comprometidos Acesso em 12.Jul.2016.

COUTO, Mia (2007). Terra Sonâmbula. São Paulo, Companhia das Letras. . (2016). Official Website. http://www.miacouto.org Acesso em 10.Jun.2016.

HARVEY, David (2003). O novo imperialismo. Adail Sobral e Maria Stela Gonçalves (Trad.). São Paulo: Edições Loyola.

DELEUZE, Gilles; GUATTARI, Félix (1997). Mil platôs - Capitalismo e esquizofrenia. Vol.5. Peter Pál Pelbart e Janice Caiafa (Trad.). São Paulo: Ed. 34.

FANON, Frantz (1979). Os condenados da terra. 2.ed. Prefácio de Jean-Paul Sartre. José Laurenio de Melo (Trad.). Rio de Janeiro. Civilização brasileira. HALL, Stuart (2001). Da Diáspora: Identidades e mediações culturais. Belo Horizonte: Editora UFMG; Brasília: Representação da Unesco no Brasil. TUTIKIAN, Jane (2006). Velhas identidades novas: o pós-colonialismo e a emergência das nações de língua portuguesa. Porto Alegre: Sagra Luzzato. 
SPIVAK, Gayatri Chakravorty (2010). Pode o subalterno falar? Sandra Regina Goulart Almeida, Marcos Pereira Feitosa e André Pereira Feitosa (Trad.). Belo Horizonte: Editora UFMG.

SPIVAK, Gayatri Chakravorty et al (2008). Estudios postcoloniales: ensayos fundamentales. Marta Malo Madri (Trad.). Queimadas Graficas.

FERREIRA, Manuel (1975). No Reino de Caliban. Seara Nova, Lisboa.

Jorge Alves Santana é Pós-Doutor em Letras pelo Pós/Lit - UFMG. Professor da UFG/ Regional Goiânia. Membro Permanente do Programa de Pós-Graduação em Letras e Linguística (com Mestrado e Doutorado). Área de Estudos Literários e Culturais. Lattes: http:// buscatextual.cnpq.br/buscatextual/visualizacv.do?id=K4799627A2. www.letras.ufg.br. Contato: jorgeufg@bol.com.br 